\title{
The meaning of being a pharmacist: Considering the professional identity development of first-year pharmacy students
}

\author{
M van Huyssteen, $\mathrm{PhD}$; A Bheekie, $\mathrm{PhD}$ \\ School of Pharmacy, Faculty of Natural Science, University of the Western Cape, Bellville, South Africa
}

Corresponding author: $M$ van Huyssteen (mvanhuyssteen@uwc.ac.za)

Background. Professional identity underpins an individual's perspective in the way they evaluate, learn and make sense of their professional practice. In pharmacy education, the development of a professional identity has remained problematic, which may largely be attributed to the dearth of literature that properly defines, teaches and assesses professionalism.

Objectives. To identify and describe first-year pharmacy students' professional identity and determine whether it changed during the first semester of the 'Introduction to pharmacy' course.

Methods. Students had to write three sequential reflective reports in which they were expected to identify critical experiences since their enrolment. These served as reference points from which they could frame their sense of professional identity. After grading, each set of reports was ordered according to total marks allocated, of which every tenth report was selected for thematic analysis.

Results. Baseline reports indicated that students had a largely stereotypical view of the pharmacist as medicine supplier. Subsequent reports showed a shift in perspective, as students articulated a more complex role for the pharmacist, distinguished between the pharmacist's role and that of other health professionals, and formulated the pharmacist's positive value for society.

Conclusion. Our findings describe the attempts of first-year pharmacy students to internalise a professional identity during a first-semester module. By applying concepts of social identity theory to sequential reflective assignments, an emerging professional identity could be interpreted, which was denoted by an increasing sense of belonging to the pharmacy profession.

Afr J Health Professions Educ 2015;7(2):208-211. DOI:10.7196/AJHPE.423

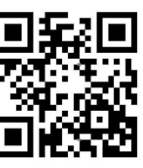

Professional identity underpins an individual's perspective in the way they evaluate, learn and make sense of their professional practice. ${ }^{[1]}$ Higher education institutions are being put under increasing pressure to prepare students for the world of work ${ }^{[1]}$ by producing autonomous graduates who have the ability to make evidence-based decisions in line with their values in rapidly changing, complex and contradictory situations. ${ }^{[2]}$ This requires practice-based curricula that contribute to the development of professional identities. Medical educators have therefore attempted to conceptualise professional identity development in terms of their teaching and learning contexts. ${ }^{[3-5]}$ Social identity theory has been proposed and applied as one conceptual framework for the understanding of professional identity development, as it aims to define and explain the social and individual factors and processes that influence an individual's sense of belonging to a specific social group, which encompasses professional groups. ${ }^{[3-7]}$

In pharmacy education, the development of a professional identity has remained problematic, which may largely be attributed to the dearth of literature that properly defines, teaches and assesses professionalism. ${ }^{[8]} \mathrm{A}$ recent study among first- and third-year pharmacy students found that a professional identity is underpinned by a sound knowledge of basic science $^{[9]}$ instead of professional practice. Some postulate that the lack of pharmacy students' socialisation into professional practice may be a reason for the so-called 'crisis in professionalism. ${ }^{[10]}$ A recent systematic review of higher education literature revealed a general scarcity of articles that comprehensively define and explore the teaching and learning of professional identity development. ${ }^{[1]}$ Nonetheless, the literature seems to agree on a two-pronged approach to underpin development of a professional identity during higher education: (i) it should enable student participation in experiences likely to be encountered in professional practice (also referred to as professional socialisation); and (ii) it should facilitate the student's ability to make meaning ${ }^{[2]}$ of these experiences through reflection and critical self-reflection. ${ }^{[1,2,11,12]}$

The purpose of this enquiry was to identify and describe first-year pharmacy students' professional identity and determine whether it changed during the first semester of the 'Introduction to pharmacy' course. In this article, sequential written assignments in the form of reflective critical incident reports were analysed. The structure of this article is as follows: firstly, some of the concepts of professional identity development are discussed, primarily in terms of social identity theory. ${ }^{[13]}$ Secondly, the learning environment is contextualised in terms of the processes of socialisation and reflection. Lastly, the findings attempt to align students' progressive descriptions of 'what it means to be a pharmacist' with concepts of social identity theory that charaterise the identity development process.

\section{Professional identity formation and learning}

According to the social identity theory, a person usually has a number of social identities ${ }^{[13]}$ (e.g. gender, age, language, culture, socioeconomic class, personality type, occupation) that contribute to the construction of an allencompassing self-identity. Each social identity is contextualised in terms of the status of the specific social group (e.g. women, 30-something, Afrikaans, white, middle class, introvert, pharmacist) and power relationships in society, ${ }^{[14]}$ which shape a social group's stereotypical image (or 'social title'). Through the cognitive process of self-categorisation, an individual may choose to identify with certain social groups. ${ }^{[3]}$ This identification 
process defines who a person is - the in-group (e.g. pharmacist) - as well as who a person is not - the out-group (e.g. doctor/nurse). Group membership is usually associated with cultivating increasingly positive attitudes towards the in-group by appreciating its diversity and differentiating this diversity from out-groups. ${ }^{[3]}$ The development of an in-group mentality is made accessible when an individual choosing to assume that social identity (e.g. pharmacist) participates in activities associated with the group (e.g. dispensing of medicine) or social engagements that require the salience of that social identity (e.g. advising patients about medicine). There is a natural tendency to link good attitudes to the in-group, resulting in the out-group being thought of as the opposite of the in-group (bad attitudes). These attitudes towards the out-group tend to have a homogenising effect in the mind of the individual, which gives rise to social stereotyping of this group.

The 'development of a professional identity' is primarily concerned with the process of integrating a new social identity into an individual's self-identity. The identity reconstruction process is dependent on the socialisation of an individual in appropriate roles and forms of participation in the community, and the ability to make meaning of socialisation encounters. ${ }^{[13]}$ The aim of providing students with professional socialisation encounters (such as interacting with pharmacists, evaluating what they do, or actively seeking information about the profession ${ }^{[9]}$ ) is to increase the salience of professional identity, thus providing the opportunities to add personal meaning to the new social identity. This experience of the making of meaning allows students to construct their own 'knowledge of' the profession as opposed to 'knowledge about' the profession (which they are taught in class). By doing so, students are provided opportunities that might cultivate a sense of belonging to the professional group, as 'one cannot develop a practice-centred identity simply by learning about the practice. ${ }^{[10]}$ The internalisation of a professional identity involves a change in what we know and how we know what we know. Thus, pharmacists may interpret their professional identity in different ways, as the process of internalisation is heavily dependent on a person's ability to shape a coherent meaning. ${ }^{[15]}$ Meaningmaking is limited by the level of complexity of an individual's frame of reference (beliefs, feelings and values), which is dependent on cognitive, emotional and social aspects of self-identity. ${ }^{[15]}$
Therefore, the internalisation of a 'new' identity involves an increase in the complexity of an individual's perspective or frame of reference. ${ }^{[12]}$ The latter may become more complex if it is to be identified, analysed and challenged through critical reflection and self-reflection. ${ }^{[2]}$ Initially, this process may manifest in students through feelings of discomfort, confusion and contradiction. It is important for them to be aware that feelings of discomfort are potential markers of a shift in identity ${ }^{[5]}$ and for teachers to facilitate this understanding for students to drive their own growth.

\section{Setting and structure of enquiry}

The School of Pharmacy, University of the Western Cape (UWC) launched its new curriculum in 2013, which included two pharmacy-focused modules for first-year students. This was the first time that staff from the School of Pharmacy had been involved in teaching first-year students. This article focuses on the first-semester module entitled 'Introduction to pharmacy'. The aim of this module was to announce the start of the journey in becoming a pharmacist, focusing specifically on the concept of 'what it means to be a pharmacist'. Our enquiry was primarily explorative and descriptive in design. It comprised sequential reflective written assignments (Fig. 1), embedded within a continuum of didactic lectures providing explicit 'knowledge about' pharmacy and pharmacists, interspersed with socialisation encounters and group reflection.

Three sequential written assignments followed the structure of a reflective critical incident report. ${ }^{[11]}$
Each assignment consisted of a short narrative account of a critical experience identified by the student, interpreted as a significant learning moment, turning point or moment of realisation, which they thought contributed to their personal or professional identity development. The purpose of the first assignment was to gauge the first-year students' interpretations of 'what it means to be a pharmacist' before introducing the pharmacy curriculum and influence of lecturers (Fig. 1). This assignment served as a reference point from which later shifts in students' descriptions could be determined.

The first socialisation component for the students was a service-learning experience at a primary school in an underserved community in Cape Town. The students were tasked to talk to groups of learners (Grades 4 - 7) for 1 hour, trying to establish what the learners knew about factors affecting their health. The service-learning experience was followed by a 2-hour group reflection on campus. ${ }^{[12]}$ The purpose of group reflection was for students to share experiences that tended to be different or contradictory to their personal frame of reference (beliefs and morals about the world). Contradictions between a personal frame of reference and real-world experiences may lower an individual's self-esteem and thus threaten the professional identity development process. Dialogue with different group members offers as many perspectives for the interpretation of the incident and eases the initial contradiction, affording a more inclusive interpretation of the experience. The second written assignment focused specifically on a critical incident that

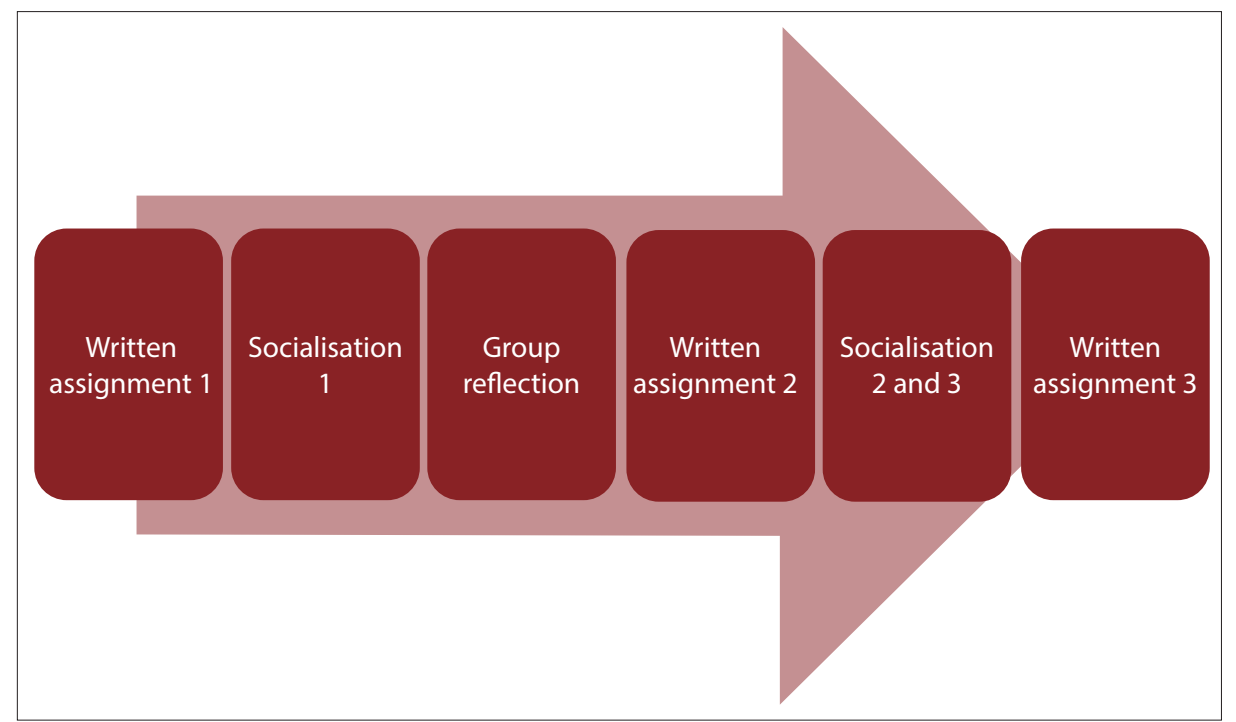

Fig. 1. Sequence of investigation. 
enabled students to examine their self-identity and how their personal frame of reference correlated or did not correlate with their interpretation of their professional identity.

The second socialisation component was an interprofessional learning component completed at the Interdisciplinary Teaching and Learning Unit at UWC. It required students to participate in interprofessional group work (with students studying dentistry, occupational therapy, etc.) for 2 hours once a week over 7 weeks, and covered topics of health, social development and primary healthcare as part of their first-semester module.

The third socialisation component was an opportunity for students to attend a talk and engage with 3 guest pharmacists for $\sim 1$ hour, each practising in a different sector of pharmacy (industry, public primary healthcare and hospital (clinical) sector). These interactions aimed to expose students to a variety of potential role models and practice environments and it was hoped to reduce the perception of the stereotype pharmacist. ${ }^{[3]}$

The three sequential written assignments formed part of the formative assessment mark for the module. Each assignment was graded according to a reflection rubric that included four main assessment criteria: clear and expressive description of the critical incident; analysis of how the incident contributed to the understanding of self, others and the profession; open, non-defensive self-appraisal of one's own frame of reference; and language structure and use. Feedback on assignments focused on stimulating the students to re-examine their frame of reference relative to their experiences (on or off campus). The allocation of marks for each sequential assignment incrementally increased for the analysis and self-appraisal criteria and decreased for description and structure criteria to explore the depth of their critical analysis skills. The first and third assignments were marked by one individual assessor, but the second assignment was marked by three independent assessors using the reflection rubric. Inter-assessor variability should not have a marked effect on the findings of this investigation, as the grades of the students do not necessarily correlate with the strength of their professional identity. The grades were used as a tool to facilitate the sampling process. Each set of assignments (first, second and third) was ranked in order of the highest to the lowest score, of which every tenth assignment was sampled. Thematic analyses were done separately for each set of assignments.

\section{Results and discussion}

Findings are presented in the order in which the assignments were written. The first set of assignments showed that students largely viewed the pharmacist as different from themselves and described critical incidents from the patient's perspective. Students tended to describe the stereotypical role of the pharmacist, with most of the critical incidents relating to medicines. Students' perceived knowledge about 'medicine' was dominated by images of pharmacists dispensing it and advising people on how to administer it. There were isolated examples of caring and professional conduct. Students tended to describe a pharmacist in terms of having scientific knowledge (mainly chemistry and biology) closely related to the requirements for being accepted into the pharmacy course, probably because this is what they had been exposed to. Students were not cognizant of the values of socialisation skills. These overwhelmingly stereotypical descriptions of the poorly communicating, independent and intelligent pharmacist were in line with findings from a previous interdisciplinary study conducted in the UK with neophyte undergraduate students (including audiologists, doctors, midwives, nurses, occupational therapists, pharmacists, physiotherapists, podiatrists, radiographers and social workers) who had to rate the professional attributes of different types of healthcare workers. ${ }^{[7]}$ In another study from the UK, which compared the perception of professional identity between first- and third-year pharmacy students, the former tended to delay their identity development until they acquired a broad scientific knowledge..$^{[9]}$ The abovementioned findings reinforce the notion that early professional identity development during pharmacy education is particularly weak. This is hardly surprising, as the students are mainly exposed to the natural sciences at the School of Pharmacy rather than professional practice during their first year.

After the first socialisation encounter, the second set of assignments described students' first experiences of 'being' a pharmacy student. One student noted that 'I felt appreciated and important'. Another student described this in terms of her feeling of belonging to the profession: 'As pharmacy students we were wearing our lab coats and lanyard as to respect and represent the pharmacy job, so that even the learners can see we did not send ourselves, but we have been sent.' The previous two quotes described students' experiences of 'being perceived as' pharmacy students rather than 'being' pharmacy students. This is not surprising, as they have had little exposure to the pharmacy practice setting. Other students described experiences with a more internal focus of their engagements with others. This was evident from some students expressing their feelings of unease at the new responsibility that went with 'being' a pharmacy student: 'These children were letting me into their lives and it was up to me to listen and practise confidentiality with the important information that they had rendered on my shoulders.' By making some of the roles of the pharmacist accessible, students could start identifying qualities of a pharmacist, such as empathy, adaptability, compassion and humility, on the basis of personal experience and not only from what they were taught in class. Students realised that the role of the pharmacist did not only require (stereotypical) knowledge and skills, but demanded personal maturity and the development of self-responsibility. This realisation seemed to add value to and respect for the role of the pharmacist in society, as illustrated below:

'The reason why this incident had this effect on me I think it's because I did not know that becoming a pharmacist was all about care taking and making a great change in someone's life not by just dispensing medicine but also helping them by giving them advice and because I had little knowledge before going to that school but now I am no more in that nut shell.'

In the third set of assignments some students started to express their perceptions of the undervalued role of the pharmacist in society. With regard to identity development, this may suggest that students were starting to identify with pharmacists as the in-group by delineating professional boundaries with out-groups, as noted in the following: 'The doctor is the custodian of diagnosis and the pharmacist the custodian of medicines.' Furthermore, students reported a broader and deeper understanding of the role of the pharmacist. They valued the core competencies that pharmacists were required to attain when handling medicines, i.e. discovery and design of new products and industry-linked activities such as manufacture, storage and distribution of bulk supplies. They also seemed to articulate the attributes that a good pharmacist should have, e.g. communication as an especially valuable skill. Students expressed their desire to be more engaging/patient-centred and asserted to fulfil this role in future. Furthermore, they commented on the personal growth they experienced during this course: 'Not only have I learnt so much about the pharmacy 
profession but I have come to know many things about myself that I was unaware of.' This is especially important, because a complex frame of reference, usually associated with maturity, is important for the reflective ability needed to develop a strong professional identity. ${ }^{[2,5,15]}$

Limitations of this enquiry include that the results were based on selfreport and linked to a mark for formative assessment, which might have made the students identify with a pharmacist more positively than was the case. Another limitation might have been that students' professional socialisation encounters did not occur in a pharmacy and were not facilitated by a pharmacist, i.e. an atypical practice environment. This environment may have diluted the experience of a pharmacist identity in favour of a more generic healthcare worker identity (non-traditional pharmacist identity). However, this is a common problem in pharmacy education, where some educators perceive the role of the pharmacist to be more 'traditional', while others recognise the need of being a more active participant and decision-maker in the healthcare team and with the patient. ${ }^{[8]}$ This distinction is important because it seems to be the cause of the 'realistic disenchantment' that some pharmacy students experience during the latter years of study, when confronted with the gap between theory and practice. ${ }^{[8]}$

\section{Conclusion}

Our findings describe first-year pharmacy students' attempts to internalise a professional identity during a first-semester module. By applying concepts of social identity theory to sequential reflective assignments, an emerging professional identity could be interpreted, which was denoted by an increasing sense of belonging to the pharmacy profession. It is recommended that studies on professional identity continue to track the development of identity over the undergraduate period, as ongoing inconsistencies may develop between theory and practice - the traditional role of the pharmacist being increasingly assumed by the student. The idea of an evolving identity is in line with a more general assumption in higher education, i.e. that 'Educators must now design curricula that will help graduates engage with a constantly shifting professional identity. Rather than help build armour that they can then face the world and their clients with over the course of their career, educators must now help students to see that they are constantly becoming professionals and that their identity development is increasingly fluid. ${ }^{[1]}$

\section{References}

1. Trede F, Macklin R, Bridges D. Professional identity development: A review of the higher education literature. Studies in Higher Education 2012;37(3):365-384. [http://dx.doi.org/10.1080/03075079.2010.521237]

2. Lewis P, Forsythe GB, Sweeney P, et al. Identity development during the college years: Findings from the West Point longitudinal study. Journal of College Student Development 2005;46(4):357-373. [http://dx.doi org/10.1353/csd.2005.0037

. Burford B. Group processes in medical education: Learning from social identity theory. Med Educ 2012;46:143 152. [http://dx.doi.org/10.1111/j.1365-2923.2011.04099.x]

4. Goldie J. The formation of professional identity in medical students: Considerations for educators. Med Teach 2012;34:e641-e648. [http://dx.doi.org/10.3109/0142159X.2012.687476]

5. Jarvis-Selinger S, Pratt DD, Regehr G. Competency is not enough: Integrating identity formation into the medical education discourse. Acad Med 2012;87(9):1185-1190. [http://dx.doi.org/10.1097/ACM.0b013e3182604968]

6. Adams K, Hean S, Sturgis P, et al. Investigating the factors influencing professional identity of first year health and social care students. Learning in Health and Social Care 2006;5(2):55-68.

7. Hean S, Macleod Clark J, Adams K, et al. Will opposites attract? Similarities and differences in students' perceptions of the stereotype profiles of other health and social care professional groups. Journal of Interprofessional Care of the stereotype profiles of other health and social care professi
2006;20(2):1-20. [http://dx.doi.org/10.1080/13561820600646546]

8. Rutter PM, Duncan G. Can professionalism be measured? Evidence from the pharmacy literature. Pharmacy Practice 2010;8(1):18-28

9. Taylor KMG, Harding G. The pharmacy degree: The student experience of professional training. Pharmacy Education 2007;7(1):83-88. [http://dx.doi.org/10.1080/15602210601149383]

10. Duncan-Hewitt W, Austin Z. Pharmacy schools as expert communities of practice? A proposal to radically restructure pharmacy education to optimize learning. Am J Pharmaceutical Educ 2005;69(3):370-380.

1. Branch WT. Use of critical incident reports in medical education. J Gen Intern Med 2005;20:1063-1067.

12. Mezirow J. An overview on transformative learning. In: Illeris $\mathrm{K}$, ed. Contemporary Theories of Learning Learning Theorists ... in Their Own Words. New York: Routledge, 2009:90-105.

13. Tajfel H. Human Groups and Social Categories: Studies in Social Psychology. Cambridge: Cambridge University Press, 1981:1-369.

14. Hogg MA, Abrams D. Social Identitifications: A Social Psychology of Intergroup Relations and Group Processes. London: Routledge, 1998:1-268.

15. Kegan R. In Over Our Heads: The Mental Demands of Modern Life. Massachusetts: Harvard University Press, 1994:1-396. 